\title{
Transcatheter aortic valve replacement with a focus on transcarotid: a review of the current literature
}

\author{
Issa Pour-Ghaz ${ }^{1}$, Joel Raja ${ }^{1}$, Mahmoud Bayoumi ${ }^{1}$, Theodore Manolukas ${ }^{1}$, Rami N. Khouzam ${ }^{2}$, \\ Uzoma N. Ibebuogu ${ }^{2}$ \\ ${ }^{1}$ Department of Internal Medicine, ${ }^{2}$ Division of Cardiovascular Diseases, Department of Medicine, University of Tennessee Health Science Center, \\ Memphis, TN, USA \\ Contributions: (I) Conception and design: I Pour-Ghaz, UN Ibebuogu, RN Khouzam; (II) Administrative support: UN Ibebuogu, RN Khouzam; (III) \\ Provision of study materials or patients: None; (IV) Collection and assembly of data: I Pour-Ghaz; (V) Data analysis and interpretation: I Pour-Ghaz; \\ (VI) Manuscript writing: All authors; (VII) Final approval of manuscript: All authors. \\ Correspondence to: Issa Pour-Ghaz, MD. Internal Medicine Resident Physician, PGY-2, University of Tennessee Health Science Center 956 Court \\ Ave., Suite H314, Memphis, TN 38163, USA. Email: ipourghaz@gmail.com.
}

\begin{abstract}
Valve replacement in high-risk patients with severe aortic stenosis has undergone a huge paradigm shift in the recent years in terms of procedural details and vascular access site for patients who have poor peripheral access. Carotid artery is one of the more promising access sites which has been proven to provide a good alternative site with comparable outcomes to transfemoral approach. In this manuscript, we will provide a review of the current literature on transaortic, transapical, transaxillary and transcarotid approaches to transcatheter aortic valve replacement (TAVR) while focusing on the transcarotid approach.
\end{abstract}

Keywords: Transcarotid transcatheter aortic valve replacement (transcarotid TAVR); transcatheter aortic valve replacement (TAVR); transcarotid; transapical; transfemoral; transaxillary; transaortic; aortic stenosis (AS)

Submitted Jun 16, 2019. Accepted for publication Jun 28, 2019.

doi: $10.21037 /$ atm.2019.07.11

View this article at: http://dx.doi.org/10.21037/atm.2019.07.11

\section{Introduction}

Aortic valve disorders comprise the most common type of valve disorders and its prevalence of moderate to severe aortic stenosis (AS) can be as high as $2.8 \%$ in the population aged 75 years and older (1). Surgical aortic valve replacement (SAVR) has traditionally been the gold standard for treatment of severe symptomatic AS. Since transcatheter aortic valve replacement (TAVR) was first performed in 2002, it has emerged as an acceptable therapeutic option for such patients who are at high-risk for SAVR and accounts for approximately $80 \%$ of the procedures (2-5). More recently, TAVR has shown promising results in intermediate and low risk groups (6-8). In addition to the more common transfemoral approach (TF), there is a multitude of approaches for TAVR including transapical, transaxillary, transcaval, transaortic, and transcarotid which account for the remaining $20 \%$ of the procedures while the TC itself accounts for approximately $10 \%$ of the alternative procedures $(2,9,10)$.

\section{Discussion}

\section{Transfemoral}

TF has become the preferred access for TAVR due to its proven superiority compared to other approaches and is favored by the international guidelines and accounts for approximately $80 \%$ of the procedures $(11,12)$. Its superiority in terms of procedural outcomes has been extensively studied and proven in cohort studies with lesser procedural mortality and higher success rates (13). The percutaneous puncture and suture pre-closure are the preferred techniques for the TF with ideal vessel entry point being between the inferior epigastric artery and the femoral bifurcation (14). However, even though the TF is the optimal approach for TAVR, in up to a third of the cases this route may not be optimal. Primary contraindications include unsuitable iliofemoral vessel size, a tortuous anatomy, or significant atherosclerotic disease, hence, 
alternate routes of implantation are required $(2,15,16)$. For this purpose, the multimodal investigation by utilizing echocardiography, computed tomography (CT) and cardiac magnetic resonance (CMR) imaging of structural heart disease are of utmost value (17).

Echocardiography is of extreme importance in planning of TAVR due to its ability not only to visualize the valve and provide important information regarding the cardiac function, but also adding information regarding the aortic root complex, aortic annulus, calcification and aortic valve area (18). Transthoracic echocardiography and transesophageal echocardiography are also applied during the procedure for assessment of pre- and post-procedure valve function and assessment of valve function in follow-up (19). CT is also vital in procedural planning and assessment of patient vasculature prior to surgery. It can provide great details of the aortic root, aortic valve dimensions, aortic annulus, and aortic angle (20). It can also provide outstanding details regarding the peripheral vasculature anatomy, aorta, iliofemoral vessels and atherosclerosis burden, as well as carotid artery anatomy (21). These data points all play an important role when planning the best route for approach of TAVR and follow-up after deployment $(22,23)$. CMR imaging is another method used for aortic valve assessment. Similar to CT of aortic valve, CMR can provide information regarding the valve size, severity of AS, best approach to be used and post-implant follow-up (24). More importantly it can be used for TAVR planning in patients with contraindication to CT imaging due to comorbid conditions or allergies. Mayr et al. showed that there was good correlation between CT and CMR for TAVR procedure planning in terms of aortic annulus and aortoiliofemoral diameter measurements and comparable decisions regarding prosthesis size (25).

\section{Transapical}

Transapical approach (TA) approach was the first alternate method to be described when the TF was not feasible, especially when there was significant iliofemoral disease. TA method is the only TAVR method that is anterograde and provides easy valve crossing due to the anatomical approach and avoids cardiopulmonary bypass and sternotomy (26-29). The procedure involves exposing the apex of the left ventricle by performing a mini-thoracotomy and placing purse string sutures. Transesophageal echocardiogram is then used to identify an optimal puncture location and insertion of a $5 \mathrm{~F}$ sheath. Aortic valve is then crossed in an anterograde fashion and the diagnostic wire and valve wire are introduced, and the valve is deployed. Rapid ventricular pacing is used at the time of suture placement for reducing the risk of bleeding (9). This approach has had declining popularity in the recent years and has gone from accounting for nearly $20 \%$ of the alternative approach subset to less than $5 \%$ (2).

Lardizabal et al. (2015) performed a comparison of the TA and transaortic approach (TAo) procedures and found that all-cause mortality at 30 days to be similar between the two groups. Cardiovascular mortality was significantly higher in the TA group and after a median follow-up of 23 months Kaplan-Meier analysis showed a persistent trend towards higher probability of long-term survival in the TAo group (30). Thourani and colleagues also showed that post-operative and 30-day outcomes was not significantly different between the TA, TAo, and TC, however, they did show a tendency towards an increased observed operative mortality (31). O' Sullivan and colleagues echoed the previous findings where there was no significant difference in incidence of stroke, transient ischemic attacks, major bleeding and pacemaker implantation. They also demonstrated no significant difference in 30-day mortality between TAo and TA groups (32).

Major limitations regarding the TA method is its relatively invasive nature and end-result of myocardial damage post-procedure demonstrated by apical hypokinesis. Al-Hijji et al. (2018) demonstrated the lower ability of left ventricular ejection fraction post TA approach when compared to the TF method (33). This point has been demonstrated by subset analysis of the PARTNER I trial which showed that the TA approach was associated with increased cardiac mortality in subjects with less than $50 \%$ ejection fraction and was associated with delayed and less robust improvement in left ventricular function (34). There have also been reported cases of left ventricular aneurysm and rupture in rare cases secondary to the scar tissue formation post procedure (32). Other well-known complications of the TA method is increased likelihood of blood product needs, longer duration of stay at the hospital, and more likelihood of acute kidney injury (35). Another important limitation of the TA approach is the well documented increase in mortality post procedure (36). Hence, the use of TA approach in light of newer methods of TAVR needs extensive consideration especially since most of these individuals have limitations that can make the TA approach unfavorable. 


\section{Transaortic}

TAo approach is performed through a partial sternotomy or mini-sternotomy by conducting a 2 -inch midline incision below the sternal notch after which a "mini-J" shaped sternotomy is made at the second intercostal space which exposes the proximal part of the ascending aorta. A needle is used to puncture the ascending aorta and the introducer sheath is upsized to a TAVR sheath at least $6 \mathrm{~cm}$ away from the aortic annulus. The remainder of the procedure is performed in a standard retrograde fashion for the TAVR. Chest tube is left in place after the completion of the procedure (37). Currently this approach is used in approximately less than $5 \%$ of alternative approaches for TAVR (2).

The advantage of this method lies in a few factors which include the familiarity of cardiac surgeons with partial sternotomy and ascending aorta cannulation, the swift conversion to full sternotomy if needed secondary to complication, less risk of damage to myocardium and bleeding and limited chest wall injury (38). It has been suggested to utilize the TAo method in patients with severely impaired left ventricular function, fragile apex or with significant pulmonary disease (39). It should be kept in mind that TAo has some relative contraindications including but not limited to having a porcelain aorta or previous median sternotomy, hence, patient selection and screening is of utmost importance when planning TAVR. Bapat et al. (2012) demonstrated that in their cohort, there was no significant difference in 30-day mortality compared to the transapical group and there was no statistically significant difference in rates of post-procedural need for cardiopulmonary bypass or stroke (40). Similar findings have been reported by other authors whereby the 30-day mortality was not significantly different when compared to the transfemoral and TAs (41). Chollet et al. (2018) showed that the 30-day and one-year mortality rates were similar in the TAo and transfemoral methods (42). Some of the limitations of TAo include short access site that might make using the delivery system and deployment of the valve difficult. There have been documented cases of cerebrovascular events, increased rates of new onset atrial fibrillation, and increased chances of life-threatening bleeding when using this procedure which limits its use in some patients $(38,42)$.

\section{Transaxillary}

Transaxillary approach (TAx) is one of the other methods used for TAVR. Some of the advantages of this route are shorter distance, more direct approach and increased control of the device (43). Since its first implantation by Ruge $e t a l$. and colleagues, advancements in the procedure and valve generations have made huge progress and made it more streamlined (44). Safety outcomes were studied recently by Anselmi and colleagues who showed procedural success in all cases and they did not have any acute kidney injury, periprocedural stroke, periprocedural transient ischemic attack, vascular complications or periprocedural mortality (45). This approach accounts for less than $5 \%$ of alternative (2).

This procedure is performed usually through a left axillary access due to a more direct path to the aortic annulus. The axillary artery is exposed in the anterior chest wall by using a surgical approach. Pectoralis major and minor muscles are retracted to access and expose the subclavian artery. Afterwards, either a Dacron graft is used on the artery or it is punctured directly by using a micropuncture technique or a standard access needle, thereafter a $4 \mathrm{~F}$ to $6 \mathrm{~F}$ sheath is introduced. Aortic valve is crossed, and the valve is introduced following the introduction of the stiff wire. Subsequently, the sheath is withdrawn and the purse string is sutured or the Dacron graft is oversewn (9). More recently, ultrasound is being utilized for a ultrasound guided approach (46).

There have been multiple studies which compare the TAx to other TAVR methods. Block et al. showed that in their case series of TAx patients, there were no procedural complications and patients needed minimal postoperative analgesia (47). A review of 62 cases of TAx showed use of general anesthesia in 40 (66.7\%) compared to local anesthesia in 20 (33.3\%), mainly use of left axillary approach, vascular complications in 6 of 62 patients (9.7\%), axillary artery dissection in 4 of $62(6.5 \%)$, and stroke in 2 of the 62 patients; these authors noted that the rate of vascular complications is comparable with $\mathrm{TF}$ approach and the rate of paravalvular leak is much less as compared to the TF approach (43). Similar findings of lesser paravalvular leak and valve-in-valve implantation have also been found by other authors (48). In a propensity matched analysis of the outcomes of patients undergoing TAx compared to TF, Gleason and colleagues did not find any difference between the outcomes at 30 days with a trend toward lesser need for pacemaker in the TAx group. Death or myocardial infarction rate among the two groups did not differ and the major vascular complications among the two groups were similar despite higher burden of vascular disease in 
the TAx group (49). Dahle and colleagues performed 5 consecutive TAx TAVR and they showed that the approach was successful in $100 \%$ of the patients with $0 \%$ mortality, stroke or vascular injury during the hospital stay and 30 -day follow-up. They had a $20 \%$ in-hospital pacemaker implantation rate and the average length of stay was 3 days (50).

Due to these recent findings the TAx has become increasingly more popular as a method for TAVR, however, the risks and benefits of this procedure needs to be carefully considered if there is intention for use on a patient. The mechanism of stroke in these patients is likely multifactorial owing to the higher atherosclerotic load, cerebrovascular disease, aortic arch calcifications, and aortic root angulation. Vessel size and vessel tortuosity contribute to this increased risk $(51,52)$. Such promising results and advancements in the procedure can make this approach a potential to become a favorable technique in future when an alternative method is needed.

\section{Transcarotid}

Transcarotid approach (TC) is one of the most commonly used pathways for patients who have concomitant vascular disease or poor anatomy and cannot undergo TF TAVR $(53,54)$. This method provides a direct route for aortic valve implantation and offers a shorter distance from the entry site to the aortic root (14). This procedure involves surgical exposure of the common carotid artery for an arterial needle puncture and introduction of the $6 \mathrm{~F}$ arterial sheath. Then the sheath can be upsized, and the standard valve delivery method is used. Thereafter, surgical closure of the site is done with sutures (9). It should be remembered that due to the high risk of predisposing the brain to ischemic insults, extensive cerebral and carotid imaging is required in the procedural planning by using bilateral carotid duplex ultrasound, CT of the head and magnetic resonance angiography to better characterize the circle of Willis for detailed imaging of the collateral circulation (9). The first case of TC TAVR was performed in 2010 on an 89-year-old male with symptomatic degenerative AS successfully by Modine and colleagues and since then this procedure has been replicated by many $(10,55)$. This method of intervention provides a good alternative for patients with poor vascular access and no other alternative for valve replacement. In recent application of this approach, it has accounted for nearly $10 \%$ of the alternative approach pathway used (10). Recently, Parikh and colleagues described a case of successful and uneventful TC TAVR in a patient with severe peripheral vascular disease as well as severe bilateral carotid disease which demonstrates the effectiveness of this technique (56). Use of TC approach has gradually increased in the past decade owing to the optimal outcomes and familiarity with the procedure, while the absence of stroke, major bleeding, transient ischemic attacks and acute kidney injury has been repeatedly demonstrated (10).

A benefit of TC approach is better device control and positioning due to a shorter route for access and more straight approach which gives better device control for implantation. This method enhances sheath delivery and positioning. Carotid approach also translates into earlier mobility of the patient, shorter hospital length of stay and lower risk of complications due to immobility. Bleeding risk is low in such patients and easier to control and since the access site is superficial, hemodynamic stability can be reached much faster $(10,57)$. In a 145 cohort of patients, Folliguet and colleagues reported a comparable 30-day mortality with TF. They noted minimal access complications and due to the short distance to the aortic valve, there was increased stability during the delivery of the valve. They also noted that limited pulmonary reserves and poor ejection fraction did not cause limitation for this procedure (58). Based on the recent comparison done by Overtchouk et al. and Modine et al., TC pathway provides great post-operative results comparable to the $\mathrm{TF}$ in terms of the mortality especially when compared to the newer methods which use local anesthesia and conscious sedation have similar rates of cerebrovascular events. This method also allowed for a hospital stay of as short as 4 days and immediate mobilization (59). Overtchouk and colleagues recently published the results on a cohort of 314 patients who underwent TC TAVR. They did not witness any major vascular complications and major bleeding was observed in $4 \%$ of the patients which was comparable to the TF approach. They witnessed stroke in $1.6 \%$ of the patients in the first 30 days which was lower than numbers reported by the TF approach in PARTNER 2 trial and patients had a comparable 30 -day mortality rate $(7,60)$. The median length of hospital stay was also lower than previously published data by FRANCE TAVI registry (61).

There have been several studies highlighting the safety and comparable procedural outcome of TC approach in the recent years. Chamandi and colleagues compared the procedural outcomes of TC compared to TA and TAo approach. They report that after adjustment, there was no 
Table 1 Advantages and disadvantages of different TAVR methods

\begin{tabular}{|c|c|c|c|}
\hline Methods & $\begin{array}{l}\text { Percentage of } \\
\text { application }\end{array}$ & Advantages & Disadvantages and contraindications \\
\hline Transfemoral & $80 \%$ & $\begin{array}{l}\text { Familiarity with anatomy and extensive experience; } \\
\text { shorter duration; small incision of access vessel; } \\
\text { less invasive; can be done under local anesthesia; } \\
\text { less post procedure pain; faster wound healing; less } \\
\text { infection; short hospital stay }\end{array}$ & $\begin{array}{l}\text { Closure device failure; vessel dissection; } \\
\text { unsuitable in patients with small iliofemoral } \\
\text { vessel size, tortuous vessel anatomy, or } \\
\text { significant atherosclerotic disease }\end{array}$ \\
\hline Transaortic & $<5 \%$ & $\begin{array}{l}\text { Can be used in patients with severe lung disease and } \\
\text { low ejection fraction; allows for rapid cardiopulmonary } \\
\text { bypass conversion if needed; access similar to } \\
\text { surgical aortic valve replacement }\end{array}$ & $\begin{array}{l}\text { Not suitable in patients with porcelain aorta or } \\
\text { those who have had previous sternotomy; short } \\
\text { access site; dissection; infection }\end{array}$ \\
\hline Transcarotid & $\sim 10 \%$ & $\begin{array}{l}\text { Direct access for implantation; minimal to no } \\
\text { paravalvular leak; familiarity with neck anatomy; } \\
\text { optimal device control; short hospital stay; early } \\
\text { ambulation post procedure; minimal blood loss; less } \\
\text { new onset atrial fibrillation }\end{array}$ & $\begin{array}{l}\text { Carotid artery diameter greater than } 8 \mathrm{~mm} \\
\text { without evidence of calcification or severe } \\
\text { tortuosity; patent circle of Willis and cerebral } \\
\text { circulation; stroke }\end{array}$ \\
\hline
\end{tabular}

TAVR, transcatheter aortic valve replacement.

significant difference in risk of stroke or transient ischemic attack between the two groups. TC group had significantly less new onset atrial fibrillation, major or life-threatening bleed, shorter mean hospital length of stay. The also reported a tendency towards less vascular complications in the TC group. They reported 2 times the mortality rate at 30 days in the TA and TAo groups, even though it was not statistically significant (62).

One of the major concerns regarding TC approach is the risk of potential stroke, especially when the carotid artery is involved. Major mechanism for such worry is the embolic events that can arise from carotid atheroma and valvular calcifications. In order to limit such events, thorough imaging of the carotid arteries and continuous monitoring throughout procedure together with new delivery methods have limited the risks. Multiple studies have shown the procedure to be as safe as the gold standard of TF without increase in risk of complications, mortality, morbidity and length of stay $(10,63)$. Watanabe et al. (2018) performed a retrospective study and compared TC with TF and showed that the TC TAVR was not inferior to the TF TAVR and can be preferable alternative when TF TAVR is not possible due to peripheral arterial disease (64). Thus, in patients with poor traditional access for implantation, carotid artery provides a suitable alternative for valve implantation since the risk of complications post-procedure is very low. These patients are able to ambulate more quickly and be discharged from the hospital earlier. These patients need to be worked up with thorough imaging to minimize the chances of complications. Close intraoperative monitoring can help in minimizing the risks. TC TAVR has proven to be comparable in outcomes to the gold standard of TF TAVR, hence, use of this method of approach for patients with poor peripheral access who need TAVR is a suitable alternative.

Since its introduction, TAVR has revolutionized how we approach valve replacement for patient with AS. Each of the different methods introduced since its application have certain advantages, disadvantages and contraindications (Table 1). It is through detailed imaging and consideration that the optimal method for each case can be selected and applied for optimal outcome. 


\section{Conclusions}

TAVR has become the most commonly used standard of care in patients with moderate to severe aortic valve stenosis. Recent advancements have furthered the use of TAVR in low risk patients showing promising results. The most common site for access by far is the femoral route, although a multitude of other sites are available. TF TAVR is problematic in patients with poor peripheral access and vascular disease; hence, alternative routes of access are crucial. Among the other access sites, TC approach has proven to be a promising alternative with comparable results and low complications. Studies mentioned above have shown that such patients have comparable procedural outcomes and quicker recovery times. The use of TC TAVR has consistently increased during the past decade. Due to the shorter access and more control during implantation, TC TAVR has shown very satisfactory echocardiogram results post-procedure and on follow up echocardiograms. With more advancement in access site and procedural skills, this route of access can potentially serve as a very promising default alternative access site for TAVR.

\section{Acknowledgments}

None.

\section{Footnote}

Conflicts of Interest: The authors have no conflicts of interest to declare.

Ethical Statement: The authors are accountable for all aspects of the work in ensuring that questions related to the accuracy or integrity of any part of the work are appropriately investigated and resolved.

\section{References}

1. Wee IJY, Stonier T, Harrison M, et al. Transcarotid transcatheter aortic valve implantation: A systematic review. J Cardiol 2018;71:525-33.

2. Overtchouk P, Modine T. Alternate Access for TAVI: Stay Clear of the Chest. Interv Cardiol 2018;13:145-50.

3. Murdock JE, Jensen HA, Thourani VH. Nontransfemoral Approaches to Transcatheter Aortic Valve Replacement. Interv Cardiol Clin 2015;4:95-105.

4. Panchal HB, Ladia V, Amin P, et al. A meta-analysis of mortality and major adverse cardiovascular and cerebrovascular events in patients undergoing transfemoral versus transapical transcatheter aortic valve implantation using edwards valve for severe aortic stenosis. Am J Cardiol 2014;114:1882-90.

5. Praz F, Wenaweser P. Transcatheter Aortic Valve Replacement via the Transcarotid Access. Circ Cardiovasc Interv 2018;11:e007459.

6. Leon MB, Smith CR, Mack M, et al. Transcatheter aortic-valve implantation for aortic stenosis in patients who cannot undergo surgery. $\mathrm{N}$ Engl J Med 2010;363:1597-607.

7. Leon MB, Smith CR, Mack MJ, et al. Transcatheter or Surgical Aortic-Valve Replacement in Intermediate-Risk Patients. N Engl J Med 2016;374:1609-20.

8. Mack MJ, Leon MB, Thourani VH, et al. Transcatheter Aortic-Valve Replacement with a Balloon-Expandable Valve in Low-Risk Patients. N Engl J Med 2019;380:1695-705.

9. Young MN, Singh V, Sakhuja R. A Review of Alternative Access for Transcatheter Aortic Valve Replacement. Curr Treat Options Cardiovasc Med 2018;20:62.

10. Azmoun A, Amabile N, Ramadan R, et al. Transcatheter aortic valve implantation through carotid artery access under local anaesthesia. Eur J Cardiothorac Surg 2014;46:693-8; discussion 698.

11. Nishimura RA, Otto CM, Bonow RO, et al. 2017 AHA/ ACC Focused Update of the 2014 AHA/ACC Guideline for the Management of Patients With Valvular Heart Disease: A Report of the American College of Cardiology/ American Heart Association Task Force on Clinical Practice Guidelines. Circulation 2017;135:e1159-95.

12. Adams DH, Popma JJ, Reardon MJ, et al. Transcatheter aortic-valve replacement with a self-expanding prosthesis. N Engl J Med 2014;370:1790-8.

13. Agarwal S, Tuzcu EM, Stewart W, et al. Comparison of multicenter registries and randomized control trials for transcatheter aortic valve replacement (TAVR). Indian Heart J 2013;65:400-11.

14. Pascual I, Carro A, Avanzas P, et al. Vascular approaches for transcatheter aortic valve implantation. J Thorac Dis 2017;9:S478-87.

15. Huczek Z, Wilimski R, Kochman J, et al. Common carotid artery access for transcatheter aortic valve implantation. Kardiol Pol 2015;73:478-84.

16. Madigan M, Atoui R. Non-transfemoral access sites for transcatheter aortic valve replacement. J Thorac Dis 2018;10:4505-15. 
17. Corrigan FE 3rd, Gleason PT, Condado JF, et al. Imaging for Predicting, Detecting, and Managing Complications After Transcatheter Aortic Valve Replacement. JACC Cardiovasc Imaging 2019;12:904-20.

18. Hahn RT. Use of imaging for procedural guidance during transcatheter aortic valve replacement. Curr Opin Cardiol 2013;28:512-7.

19. Vollema EM, Delgado V, Bax JJ. Echocardiography in Transcatheter Aortic Valve Replacement. Heart Lung Circ 2019;28:1384-99.

20. Al-Hassan D, Blanke P, Leipsic J. Multidetector computed tomography in transcatheter aortic valve implantation. Where we stand. Minerva Cardioangiol 2013;61:407-27.

21. Lehmkuhl L, Foldyna B, Haensig M, et al. Role of preprocedural computed tomography in transcatheter aortic valve implantation. Rofo 2013;184:941-9.

22. Marwan M, Achenbach S. Role of Cardiac CT Before Transcatheter Aortic Valve Implantation (TAVI). Curr Cardiol Rep 2016;18:21-30.

23. Salgado RA, Leipsic JA, Shivalkar B, et al. Preprocedural CT evaluation of transcatheter aortic valve replacement: what the radiologist needs to know. Radiographics 2014;34:1491-514.

24. Rogers T, Waksman R. Role of CMR in TAVR. JACC Cardiovasc Imaging 2016;9:593-602.

25. Mayr A, Klug G, Reinstadler SJ, et al. Is MRI equivalent to CT in the guidance of TAVR? A pilot study. Eur Radiol 2018;28:4625-34.

26. Walther T, Simon P, Dewey T, et al. Transapical minimally invasive aortic valve implantation: multicenter experience. Circulation 2007;116:I240-5.

27. Walther T, Dewey T, Borger MA, et al. Transapical aortic valve implantation: step by step. Ann Thorac Surg 2009;87:276-83.

28. Walther T, Falk V, Borger MA, et al. Minimally invasive transapical beating heart aortic valve implantation--proof of concept. Eur J Cardiothorac Surg 2007;31:9-15.

29. Lichtenstein SV, Cheung A, Ye J, et al. Transapical transcatheter aortic valve implantation in humans: initial clinical experience. Circulation 2006;114:591-6.

30. Lardizabal JA, Macon CJ, O'Neill BP, et al. Longterm outcomes associated with the transaortic approach to transcatheter Aortic valve replacement. Catheter Cardiovasc Interv 2015;85:1226-30.

31. Thourani VH, Li C, Devireddy C, et al. High-risk patients with inoperative aortic stenosis: use of transapical, transaortic, and transcarotid techniques. Ann Thorac Surg 2015;99:817-23; discussion 823-5.
32. O' Sullivan KE, Hurley ET, Segurado R, et al. Transaortic TAVI Is a Valid Alternative to Transapical Approach. J Card Surg 2015;30:381-90.

33. Al-Hijji MA, Zack CJ, Nkomo VT, et al. Left ventricular remodeling and function after transapical versus transfemoral transcatheter aortic valve replacement. Catheter Cardiovasc Interv 2019. [Epub ahead of print].

34. Elmariah S, Fearon WF, Inglessis I, et al. Transapical Transcatheter Aortic Valve Replacement Is Associated With Increased Cardiac Mortality in Patients With Left Ventricular Dysfunction: Insights From the PARTNER I Trial. JACC Cardiovasc Interv 2017;10:2414-22.

35. Allen KB, Chhatriwalla AK, Cohen D, et al. Transcarotid Versus Transapical and Transaortic Access for Transcatheter Aortic Valve Replacement. Ann Thorac Surg 2019;108:715-22.

36. Biancari F, Rosato S, D'Errigo P, et al. Immediate and Intermediate Outcome After Transapical Versus Transfemoral Transcatheter Aortic Valve Replacement. Am J Cardiol 2016;117:245-51.

37. Lardizabal JA, O'Neill BP, Desai HV, et al. The transaortic approach for transcatheter aortic valve replacement: initial clinical experience in the United States. J Am Coll Cardiol 2013;61:2341-5.

38. Hayashida K, Romano M, Lefèvre T, et al. The transaortic approach for transcatheter aortic valve implantation: a valid alternative to the transapical access in patients with no peripheral vascular option. A single center experience. Eur J Cardiothorac Surg 2013;44:692-700.

39. Bonaros N, Petzina R, Cocchieri R, et al. Transaortic transcatheter aortic valve implantation as a first-line choice or as a last resort? An analysis based on the ROUTE registry. Eur J Cardiothorac Surg 2017;51:919-26.

40. Bapat V, Khawaja MZ, Attia R, et al. Transaortic Transcatheter Aortic valve implantation using Edwards Sapien valve: a novel approach. Catheter Cardiovasc Interv 2012;79:733-40.

41. Arai T, Romano M, Lefèvre T, et al. Direct Comparison of Feasibility and Safety of Transfemoral Versus Transaortic Versus Transapical Transcatheter Aortic Valve Replacement. JACC Cardiovasc Interv 2016;9:2320-5.

42. Chollet T, Marcheix B, Boudou N, et al. Propensitymatched comparison of clinical outcomes after transaortic versus transfemoral aortic valve replacement. EuroIntervention 2018;14:750-7.

43. Caceres M, Braud R, Roselli EE. The axillary/subclavian artery access route for transcatheter aortic valve replacement: a systematic review of the literature. Ann 
Thorac Surg 2012;93:1013-8.

44. Ruge H, Lange R, Bleiziffer S, et al. First successful aortic valve implantation with the CoreValve ReValving System via right subclavian artery access: a case report. Heart Surg Forum 2008;11:E323-4.

45. Anselmi A, Tomasi J, Giardinelli F, et al. Safety and effectiveness of the transsubclavian approach for transcatheter aortic valve implantation with the 14-F CoreValve Evolut R device. J Cardiovasc Med (Hagerstown) 2018;19:664-8.

46. Mathur M, Krishnan SK, Levin D, et al. A Step-by-Step Guide to Fully Percutaneous Transaxillary Transcatheter Aortic Valve Replacement. Structural Heart 2017;1:209-15.

47. Block M, Pitchon DN, Schwenk ES, et al. Left Subclavian Transcatheter Aortic Valve Replacement Under Combined Interscalene and Pectoralis Nerve Blocks: A Case Series. A A Pract 2018;11:332-5.

48. Petronio AS, De Carlo M, Bedogni F, et al. Safety and efficacy of the subclavian approach for transcatheter aortic valve implantation with the CoreValve revalving system. Circ Cardiovasc Interv 2010;3:359-66.

49. Gleason TG, Schindler JT, Hagberg RC, et al. Subclavian/ Axillary Access for Self-Expanding Transcatheter Aortic Valve Replacement Renders Equivalent Outcomes as Transfemoral. Ann Thorac Surg 2018;105:477-83.

50. Dahle TG, Castro NJ, Stegman BM, et al. Supraclavicular Subclavian access for Sapien Transcatheter aortic valve replacement- a novel approach. J Cardiothorac Surg 2018;13:16.

51. Bapat V, Tang GHL. Axillary/Subclavian Transcatheter Aortic Valve Replacement: The Default Alternative Access? JACC Cardiovasc Interv 2019;12:670-2.

52. Dahle TG, Kaneko T, McCabe JM. Outcomes Following Subclavian and Axillary Artery Access for Transcatheter Aortic Valve Replacement: Society of the Thoracic Surgeons/American College of Cardiology TVT Registry Report. JACC Cardiovasc Interv 2019;12:662-9.

53. Debry N, Delhaye C, Azmoun A, et al. Transcarotid Transcatheter Aortic Valve Replacement: General or Local Anesthesia. JACC Cardiovasc Interv 2016;9:2113-20.

54. Kirker EB, Hodson RW, Spinelli KJ, et al. The Carotid Artery as a Preferred Alternative Access Route for Transcatheter Aortic Valve Replacement. Ann Thorac Surg 2017;104:621-9.

55. Modine T, Lemesle G, Azzaoui R, et al. Aortic valve implantation with the CoreValve ReValving System via left carotid artery access: first case report. J Thorac Cardiovasc Surg 2010;140:928-9.

56. Parikh PB, Loh S, Gruberg L, et al. Transcarotid Transcatheter Aortic Valve Replacement as Preferred Alternative Access in a Patient With Bilateral Carotid Artery Disease. J Invasive Cardiol 2018;30:E9-10.

57. Campelo-Parada F, Rodés-Cabau J, Dumont E, et al. A Novel Transcarotid Approach for Implantation of BalloonExpandable or Self-Expandable Transcatheter Aortic Valves. Can J Cardiol 2016;32:1575.e9-1575.e12.

58. Folliguet T, Laurent N, Bertram M, et al. Transcarotid transcatheter aortic valve implantation: multicentre experience in France. Eur J Cardiothorac Surg 2018;53:157-61.

59. Overtchouk P, Modine T. A comparison of alternative access routes for transcatheter aortic valve implantation. Expert Rev Cardiovasc Ther 2018;16:749-56.

60. Overtchouk P, Folliguet T, Pinaud F, et al. Transcarotid Approach for Transcatheter Aortic Valve Replacement With the Sapien 3 Prosthesis: A Multicenter French Registry. JACC Cardiovasc Interv 2019;12:413-9.

61. Auffret V, Lefevre T, Van Belle E, et al. Temporal Trends in Transcatheter Aortic Valve Replacement in France: FRANCE 2 to FRANCE TAVI. J Am Coll Cardiol 2017;70:42-55.

62. Chamandi C, Abi-Akar R, Rodés-Cabau J, et al. Transcarotid Compared With Other Alternative Access Routes for Transcatheter Aortic Valve Replacement. Circ Cardiovasc Interv 2018;11:e006388.

63. Paone G, Eng M, Kabbani LS, et al. Transcatheter Aortic Valve Replacement: Comparing Transfemoral, Transcarotid, and Transcaval Access. Ann Thorac Surg 2018;106:1105-12.

64. Watanabe M, Takahashi S, Yamaoka H, et al. Comparison of Transcarotid vs. Transfemoral Transcatheter Aortic Valve Implantation. Circ J 2018;82:2518-22.

Cite this article as: Pour-Ghaz I, Raja J, Bayoumi M, Manolukas T, Khouzam RN, Ibebuogu UN. Transcatheter aortic valve replacement with a focus on transcarotid: a review of the current literature. Ann Transl Med 2019;7(17):420. doi: 10.21037/atm.2019.07.11 